\title{
Dynamic Euclidean Geometry: pseudo-Toulmin modeling transformations and instrumental learning trajectories
}

\author{
Dr. Stavroula Patsiomitou, (Corresponding author) \\ Ph.D., Department of Primary Education, University of Ioannina \\ MEd, Department of Mathematics, National and Kapodistrian University of Athens, Greece \\ E-mail: spatsiom@gmail.com
}

\begin{abstract}
The present paper attempts to bridge the world of DGS technology with the world Euclid bequeathed to us in his "Elements". Competence in the DGS environment depends on the competence of the cognitive analysis as students seek to decode their ideas using the tools provided by the software. The dynamic notions (e.g., dynamic point, dynamic segment, instrumental decoding, hybrid-dynamic objects, active/ "alive" representations etc.), are taken as given and form the specific /particular theoretical basis for the constructive processes. Dynamic Euclidean constructions will be considered using pseudo-Toulmin' diagrams. These considerations provide a theoretical basis for the idea that, in order to solve a mathematical construction problem in Dynamic Euclidean Geometry, we have to build up the interdependencies of tools in various sequential steps (based on theorems and definitions and the competence in using tools) which can be linked to the level of our conceptualization. The central idea is the following: Do the tools of Dynamic Euclidean Geometry determine a new kind of Geometry? Is Dynamic Euclidean Geometry a new kind of geometry? Does it have its own axiomatic system or its own undefined terms? In the paper, the notion of an instrumental learning path/trajectory is introduced as the interdependence/intradependence between dynamic tools, diagrams and mathematical objects during an instrumental decoding process.
\end{abstract}

Keywords: Dynamic geometry, Euclid "Elements", instrumental learning trajectories, Dynamic Euclidean Geometry

DOI: $10.7176 / \mathrm{JEP} / 12-9-09$

Publication date:March $31^{\text {st }} 2021$

\section{Introduction}

The present paper attempts to bridge the world of digital technology and the world Euclid bequeathed us in his "Elements". In the core of the paper are the 'dynamic' notions evoked in a DGS environment in tandem with the geometric meanings discussed in Euclidean Geometry. In my previous research studies, I have introduced through my research studies among others the following notions: LVAR with active /or "alive" representations, "instrumental decoding", "instrumental obstacles", "hybrid-dynamic objects" which helped me to articulate my thoughts on what evoked through research with DGS. These notions did not exist until the moment that I had to find a way to discuss about the new kinds of objects that exist in the Dynamic Euclidean Geometry.

First of all, I shall discuss what pushed me to explore the Euclidean meanings in a Dynamic Geometry System (DGS). Teaching geometry (e.g., formal definitions and proofs) with traditional means (for example, the geometric constructions of figures restricted to the use of only a straightedge and compass) and the school text book is still the prevailing method applied in schools. Modern mathematicians working at schools, when they face the difficulties and obstacles their students have with the understanding of formal concepts during the teaching of secondary or undergraduate geometry courses, they use alternative ways to gain the attention and understanding of their students: they emphasize more on exploration, problem solving, and real-life applications, usually using DGS, which play an important role in teaching and learning mathematics. There are 2-dimensional DGS packages, such as the Geometer's Sketchpad (Jackiw, 1991), Cabri II (Laborde, Baulac, \& Bellemain, 1988), Geogebra (Hohenwarter, 2001), Cinderella (Richter-Gebert \& Kortenkamp, 1999) etc. as well as 3-dimensional DGS packages, such as Cabri 3D (Laborde, 2004), and so on. In the paper "Dynamic Geometry: Sketchpad's Big idea" Jackiw (2009) describes the DG principles as a need for change to the existing practices:

"In 1990, Steven Rasmussen and I coined the term Dynamic Geometry to describe the mathematical world of Sketchpad. [...]. Our Dynamic Geometry principles-rapid expression, continuous and interactive direct manipulation, and the tangible experience of the consequences of variation-are powerful ideas in all domains of mathematical visualization. So, far beyond compass and straightedge geometry" (p.5)

For instance, a point in Euclidean geometry is something that has no dimension, "no part' (Fitzpatrick, 2007, p.6). 
In a DGS environment if we zoom in, on a point, we can view those of its dimensions ("diastases" in Greek) that are not null.

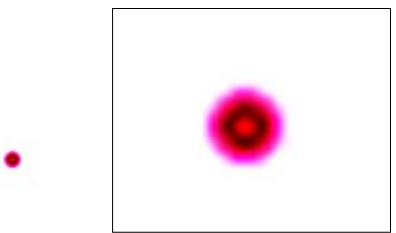

Figure 1. Screenshots of an active dynamic point in DGS

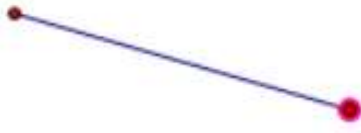

Figure 2. An active and a non-active dynamic point on the same segment

A geometric primitive as the point has not thickness, as a segment also. In figure 1, a screenshot of a point is illustrated along with the resizing of the same point in Snagit software. As we can see the point has brightness and thickness. It is a dynamic "active" point or an "alive" point (Patsiomitou, 2005, 2006, 2018). The term 'dynamic' point has been referred by many researchers to a point made in a DGS (e.g., Gonzalez and Herbst, 2009; Patsiomitou, 2011). A 'dynamic' point is a fundamental element in a dynamic construction. Hollebrands, Laborde, \& Sträßer (2008, p.165) described the distinction between the three different kinds of points in a DGS environment: (a) a free point "can be directly dragged anywhere in the plane (degree of freedom 2)", (b) a point on an object "can be dragged only on this object (degree of freedom 1)" and (c) a constructed point "cannot be grasped and dragged (degree of freedom 0 ) but moves only if an element of which it is dependent is dragged".

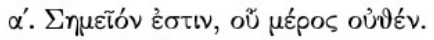

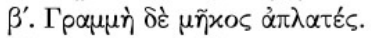

1. A point is that of which there is no part. 2. And a line is a length without breadth.

Figure 3. Euclid's Elements (Book I, Definitions) (Fitzpatrick, 2007, p.6)

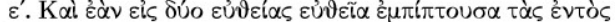

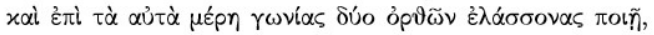

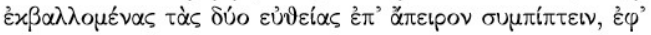

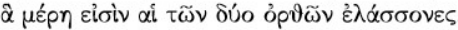

5. And that if a straight-line falling across two (other) straight-lines makes internal angles on the same side (of itself whose sum is) less than two right-angles, then the two (other) straight-lines, being produced to infinity, meet on that side (of the original straight-line) that the (sum of the internal angles) is less than two right-angles (and do not meet on the other side). . $^{\ddagger}$

Figure 4. Euclid's Elements (Book I, Postulates) (Fitzpatrick, 2007, p.7)

Hegedus (2005) also reports about points in a DGS environment as "hot-spots" something "not been an artifact of the environment but an axiomatic part of the system that allows "true" mathematical figures to be built" (p. 2). According to Hegedus (ibid.) "dragging a "hot spot" [point] illustrates how the Euclidean construction [...] has been correctly implemented in this sketch" so "the hot spot is a critical part of the construction" (p. 2). In the Sketchpad software a dynamic point is a tool. Consequently, a dynamic point can be defined in correlation with (a) its degrees of freedom and (b) its brightness, making it an alive, active tool.

Dynamic'segment is a segment made in a DGS. In my studies I also defined the term dynamic segment as follows: The 'dynamic' segment is a portion of a straight line which does not consist of points. Dynamic points can be placed independedly on the dynamic segment and move free with one degree of freedom on the path to which they belong. This means that a point placed on a segment has its two degrees of freedom transforming into one degree of freedom (Patsiomitou, 2011, 2019c, p.84)

I claim that the investigation for dynamic Euclidean objects then becomes an intellectual challenge, stemming from the need to understand why the result on screen is true. For example, the investigation of the Euclid's fifth postulate is interpreted/or illustrated in an ambiguity in a DGS environment. We cannot view the non-parallel lines "being produced to infinity" on screen. Moreover, we can have a certain amount of ambiguity in that (Figure 5). 


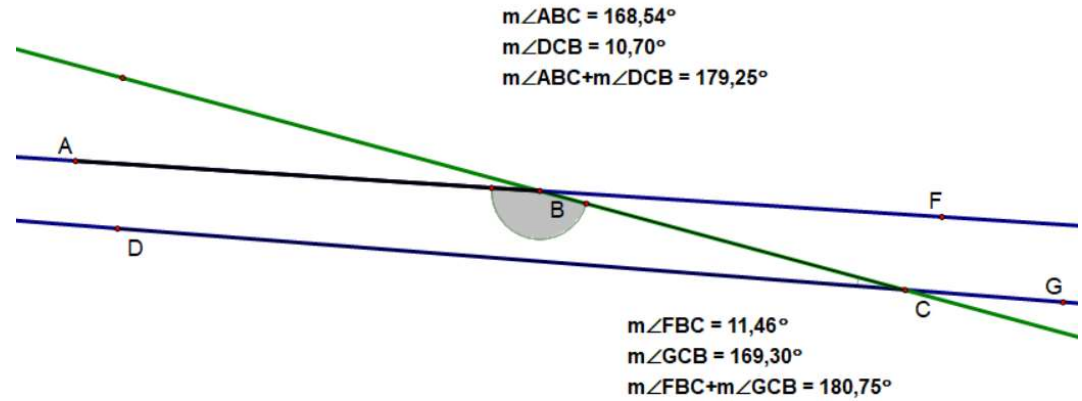

Figure 5. An illustration for the 5th postulate of Euclid's Elements in a DGS environment

Mathematical reasoning in Euclidean Geometry is scaffolded by the visual representations on screen, as their function is to recall in mind the elements to which they are connected. Janicic, Narboux, \& Quaresma (2012) also support that

"Euclid's system [...] was used for centuries. In the early twentieth century, Hilbert provided a more rigorous axiomatisation one of the landmarks for modern mathematics, but still not up to modern standards. [...]. Modern courses on classical Euclidean geometry are most often based on Hilbert's axioms. In Hilbertstyle geometry, the primitive (not defined) objects are: point, line, plane" (p.5).

Venema (2005/2012) also claims that "the first part of an axiomatic system is a list of undefined terms" (p.14). In Euclidean Geometry the words point, line and plane are undefined or cannot be defined; they serve as the building blocks for more complicated geometric shapes. In Dynamic Euclidean Geometry the addition of the word "dynamic" written previously to these terms makes them also undefined. Firstly, speaking of a DGS environment, it is important to identify the notions of geometrical entities in such an environment. I introduced the following notions in my study "From Vecten's Theorem to Gamow's Problem: Building an Empirical Classification Model for Sequential Instructional Problems in Geometry" (Patsiomitou, 2019a, p.15):

- A dynamic geometrical object (Patsiomitou, 2019a, p. 15) is every object that has been constructed in a dynamic geometry software interface. This object could be a "drawing" or a "figure" which intrinsically has dynamic properties.

- A dynamic diagram (Patsiomitou, 2019a, p. 15) is an external representation composed out of a set of rationally related dynamic objects in a DGS environment. A dynamic diagram can be a simulation of a problem modelled in the DGS environment, which includes many geometric objects and combinations of interaction techniques implemented in these objects. This definition is complementary to what Gonzalez and Herbst (2009) argue regarding the dynamic diagram as "a diagram made with DGS and that has the potential to be changed in some way by dragging one or more of its parts" (p.154).

- Adynamic section (Patsiomitou, 2019a, p. 15) is a set of dynamic diagrams that are linked to each other procedurally and conceptually, even if they may differ structurally. A dynamic section contains meanings belonging to the same class that are united or joined into a whole, which in the concrete situation symbolically means they exist in one ["alive" book] section or they are dynamically linked.

It is not within the scope of this section to discuss these issues in any more detail, but like to Goldenberg, \& Cuoco (1996) I would argue that

"Dynamic Geometry needs its own axiomatic foundation to define the objects and postulates of its environment." (cited in Jackiw, \& Sinclair, 2009, p.415).

In the current study, it is my aim to contribute to the didactics of mathematics community's reflections on these issues. I will begin with a brief presentation of a relevant theoretical framework. I will also present dynamic constructions using pseudo-Toulmin' diagrams [based on Toulmin's model]. The central idea is the following: Do the tools of Dynamic Euclidean Geometry determine a new kind of Geometry? Is Dynamic Euclidean Geometry a new kind of geometry? Does it have its own axiomatic system or --in other words-- its own undefined terms?

\section{A cognitive analysis of DGS use}

A computer microworld, such as the Dynamic Geometry Software (DGS) is an external representational system. Representations may be considered "as internal-abstractions of mathematical ideas or cognitive schemata that 
are developed by a learner through experience" (Pape \& Tchoshanov, 2001, p. 119). In my opinion (Patsiomitou, 2019c, p.42)

" a representation is both (a) an external entity (such as a verbal expression, a graph, a figure, a map, a picture), which is to say an external correspondence of objects or processes with the objects that are represented by the entities brought into being as representing objects by the modelling process, and (b) an internal mental entity, meaning a structurally equivalent modification of physical/mental objects/processes which are constructed in the mind, as a result of the processing/elaboration of information and the manipulation of objects and concepts due to the cognitive schemes which have developed in the subject's mind".

The competence to interpret a meaning between representational systems (Janvier, 1987) is necessary for students' conceptual understanding in mathematics. A DGS environment can play a fruitful and crucial role in the process of creating and evaluating conjectures which promote student creativity, and in so doing greatly contribute to developing mathematical reasoning. For instance, a very important effect on students' thinking stems from the Sketchpad software allowing the user to create sequential linking pages so that the whole Sketchpad file becomes an "alive book" (Patsiomitou, 2005, p. 63, in Greek). The "alive digital representations" (Patsiomitou, 2005, p. 67) make the whole figural diagram "alive", giving the students the potential to focus their attention on simultaneous modifications (and transformations) of objects on the screen (Patsiomitou, 2005, p. 68), also yielded important results during my investigations. In my study "An 'alive' DGS tool for students' cognitive development." (Patsiomitou, 2018) I report the following effects on students' thinking in relation to DGS software.

- A first and very important effect on students' thinking stems from the Sketchpad software allowing the user to create sequential linking pages so that the whole Sketchpad file becomes an "alive book" (Patsiomitou, 2005, p. 63, in Greek; Patsiomitou, 2014).

- A second important effect on students' thinking stems from the dynamic transformations in a DGS environment, a way of modifying an object on screen. We can change a figure's orientation, a figure's size or we can reconfigure it from its parts (Duval, 1995a, b, 1999).

- A third important effect on students' thinking occurs from dynamic constructions, that are the constructions created in a DGS environment.

- A fourth important effect on students' thinking occurs from the construction of custom tools /scripts (e.g., Patsiomitou, 2005, 2008d, 2014, 2019c). A script /custom tool combines in a concrete and sequential order the steps that have been used to accomplish the construction. Moreover, during the construction of a DGS custom tool a user determines the order the dynamic objects have to be created. In my opinion, a custom tool is an encapsulation of a sequence of primitive objects and construction commands into a new tool, combining information of the construction in a consequential mode. By constructing a custom tool, we can help students to extend the capacity of their working memory, since the knowledge the student must retain is reduced. Nonetheless, the basic underlying notion is that a student is able to codify a construction and the concrete codification shape what the student can do when s/he will encounter a new situation related to the concrete that has been abstracted and codified with the use of custom tool. A custom tool created in a DGS environment is a digital artefact. The notion of custom tool does not exist in the Euclidean Geometry. For example, the notion of "a perpendicular line custom tool" is an undefined term for Dynamic Euclidean Geometry, as it expresses the notion of a "compact" entity.

- The fifth [and most] important effect on student's thinking stems from the DGS software's dragging facilities. Sketchpad's dragging behavior transforms an object on screen moving that object on the screen.

- In previous studies I introduced the hybrid-dynamic objects (Patsiomitou, 2019a, b, c), which are intrinsically dynamic but their behavior is static in the DGS environment. These particular objects challenge students' thinking by creating the need for them to understand why the result on screen is true. For this reason, hybrid-dynamic objects impact on students' thinking.

Transformations used by the students in the DGS environment can be distinguished through the following (Patsiomitou, 2014, p.30):

- Transformation generated from the reflection, dilation, rotation, or translation of the object. Dragging on rotated (dilated, reflected, or translated) objects maintain the congruency and structural relationship between the elements of the construction.

- Transformations generated from the utilization of the action buttons tools (for example, the hide/show action button, the link button, the movement button, or animation).

- Transformations generated from the annotation of the dynamic diagram (for example, use of colours, formulations, and the trace tool). Moreover, the combination of transformations (e.g., the trace tool and 
dragging tool, the calculations and the dragging of the geometrical object's points).

- Transformations generated from the application of the custom tools. The application of custom tools reorganizes the external representation. The application of a custom tool (or the repetition of the application of a custom tool) is accomplished in a sequence of steps directly perceived by the user. Consequently, custom tools operate as a referent point for organizing, pursuing, and retrieving information.

- Transformations generated from the synthesis of the dynamic diagram.

- Transformations generated from the reconfiguration of the dynamic representation.

- Combinations of transformations due to the synthesis of the software's interaction techniques (Sedig \& Sumner, 2006).

I have also discussed several kinds of transformations and transformational results that ensue from implementing dragging on screen (Patsiomitou, 2019b, p. 43-44):

- Dragging and tracing of a geometric object (for example a point, segment or line)

Dragging a point on screen results in the transformation of its position and the simultaneous appearance of traces on screen tracking the path the point has followed or the tracks that a line passes due to dragging transformations. This action reveals in the determination of a basic property of the diagram that cannot be directly perceived from the diagram in its hybrid form, or a property of the diagram that remain stable and unaltered.

- Dragging and measuring (or calculations) the geometric object.

Dragging a point on screen leads to a change in the measurements of the object, which we have chosen to display and in its calculations. In this case, the measurements change, but the calculations may do one of two things: they may remain unchanged, indicating a stability that demonstrates the validity of a theorem or general theoretical approach (a proposal or a confirmed porisma--meaning a conclusion or an inference) or they may change, allowing the user to observe and draw conclusions from empirical results.

- Dragging and animating, or dragging, animating and tracing objects

A point on an object is dragged--for example, the vertex points of a triangle to which a point on one side is connected with motion. The animation of the diagram and the simultaneous dragging allow us to understand a condition which is not defined during the diagram's structuring process. For example, it may make us aware of a theoretical limitation that has not been determined or established before, but which appears on the diagram when it is dragged. This condition leads into an investigation of the validity of a theorem or proposal.

\section{Euclidean Geometry and DGS}

During the past decades, the researchers, the teachers and the educators ascertained the difficulties students face when they learn Euclidean geometry (e.g., Fuys et al. 1984, 1988). To this contribute the students' difficulty to release their thought from "specific contexts, so that the knowledge [will become] more general and its applicability to different situations [will be] increased" (White \& Mitchelmore, 2010, p.206), to develop deductive reasoning (Peirce, 1998/1903) and their competence to abstract thinking (e.g., Skemp, 1986; White \& Mitchelmore, 2010) which is demanded for the development of understanding of the structure in geometry, as it is performed in class. As I mentioned many times in previous works (e.g., Patsiomitou, 2008a, b, c, d), an alternative way for the teaching of geometry in schools is by using transformational geometry, which normally begins with the study of isometries. According to Whiteley (1999) transformations are the key concept of geometry. Reasoning with transformations should be a central theme of the learning of geometry. School textbooks do not describe methods how to use transformational geometry for the construction of meanings. Such a support is given by the digital school (online e-books incorporating micro-experimental files, usually created in dynamic geometry environments) (Patsiomitou, 2019c, pp.56-71).

The basic tools of a dynamic geometry environment are a) Circle (equivalent to Compass) b) Segment/Ray/Line (equivalent to Unmarked Straight Edge) c) Point (which simply enables us to place one of the fundamental 'objects' of Euclidean geometry) d) Pointer (which crucially enables us to drag objects) (Lopez-Real, \& Leung, 2004). When these tools are combined with the software's options menu, they allow the user to produce constructions which must conform with the principles of Euclidean geometry if they are to function and pass the dragging test. This means that the student has to know the theory of geometry if s/he is to generate a correct geometric construction. And while we have explained that, in the software, the constructions can contain the same mathematical logic as the constructions on paper, there are substantial differences in the manner in which the tools are used.

Competence in the DGS environment depends on the competence of the cognitive analysis which students bring to bear when decoding the utilization of software tools, based on Duval's (1995a, b) semiotic analysis of students' 
apprehension of a geometric figure. Duval (1995b, pp.145-147) has distinguished three kinds of operations, one of which is the place way, meaning an operation which changes a figure's orientation. During the development of a construction, I also think that the student has to develop three kinds of apprehension when selecting software objects which accord with the types of cognitive apprehension outlined by Duval (ibid.) namely perceptual, sequential, discursive, and operative apprehension. In concrete terms, the competence of instrumental decoding (Patsiomitou, 2011, p.362) in the software's constructions depends on the sequential apprehension of the tool's selection, the verbal apprehension of the tool's selection and a place way type of elements operation on the figure due to his/her perceptual apprehension. In concrete terms, the competence of instrumental decoding in the software's constructions depends on: a) the sequential apprehension of the tool's selection (i.e., s/he has to follow a predetermined order); b) the verbal apprehension of the tool's selection (i.e., the student has to verbalize this process), and c) a place way type of elements operation on the figure. Then $\mathrm{s} / \mathrm{he}$ has constructed the operative apprehension (Duval, 1999) of the DGS figure's elements for the construction.

Moreover, a metamorphosis could be seen as we apply one or more interaction techniques, or their combination, on the diagram's objects. The difficulty of students to imagine transformations on geometric figures during problem solving situations is based in the nature of geometrical concepts which Fischbein (1993) defined as an amalgam of: "abstract ideas on one hand and sensory representations reflecting some concrete operations on the other" (p. 14). I absolutely agree with Gawlick (2005, p.370) who argues that a dynamic approach is better suited to developing thinking at an advanced level on two counts: Firstly, tasks prepared for lower levels can be continued at higher levels, which helps familiarize students to the habit of 'discovery'. Secondly, it provides a solid basis for the van Hiele phases of learning to come, since it allows students to explore the topic in a directed orientation phase and then use their existing knowledge to build the new concepts for themselves. Students at an advanced level acquire the ability to reverse their thinking. Moreover, the reversion of thinking is developed and facilitated from the use of DGS tools (Patsiomitou, 2012a, b; 2018). An 'artefact' tool, with which the interaction takes place during the mathematical activity, is transformed into an 'instrument' tool. An instrument (Rabardel, 1995) combines both an artefactual material structure (external result) and a psychological schematic structure (internal result) directly linked to the use of the artefact (e.g., Trouche, 2003, 2004).

\section{Proof and proving}

The role of teaching and learning mathematical proof has been investigated by numerous researchers all over the world, each of whom tackled the issue from a different perspective. In my PhD thesis (Patsiomitou, 2012a) I investigated how the van Hiele theory (e.g., Fuys et al. 1984, 1988) can contribute as a base for the design of supportive materials in a classroom curriculum. Moreover, I investigated how dynamic geometry software and the meaning of Linking Visual Active Representations (e.g., Patsiomitou, 2008a, b, 2010, 2011, 2012a, b, 2019c) lead to students' reinvention of knowledge and the construction of proofs. In a short review I concluded that a mathematics education must be a process of dynamic reinvention. The comparative study followed every student on the control and experimental teams. An analysis of the results of the experimental process revealed that experimental teams' students were led to develop their level of geometrical thinking. In many studies I also investigated the interaction techniques that influenced the structure of Dynamic Hypothetical Learning Paths (DHLP), which I "designed to engender those mental processes or actions [of students] hypothesized to move [them] through a developmental progression of levels of thinking" (Clements, \& Sarama, 2004, p.83) This process was linked to the developing of strategies for solving problems, or anticipating those strands of the solution relating to individual or collaborative thought processes.

Toulmin's (1958) model of argumentation is a model which relates the involved elements: claims, data, warrants, backings, qualifiers and rebuttals in the argument formulated by an individual (or a group of students that participate). In Toulmin's (1958/1993) model “an argument comprises the claim (i.e., the statement of the speaker), data (i.e., data justifying the claim) and the warrant (i.e., the inference rule, which allows data to be connected to the claim)" (Pedemonte, 2007, p. 27). Pedemonte (2007, p.28) has presented Toulmin's basic structure of an argument constructing a figure with the three basic elements mentioned above (Figure 6).

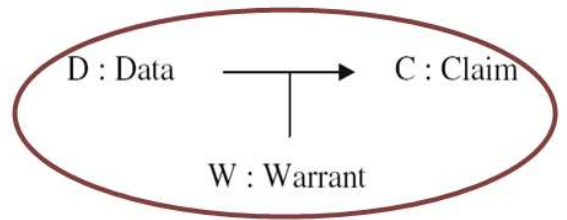

Figure 6. Toulmin's (1958) model of argumentation (Pedemonte (2007, p.28) (adapted)

In other words, Toulmin's model consists of the elements described above, which are explicit or implicit. Several 
times an argument does not include qualifiers and rebuttals. Krummheuer (1995) suggested and applied a reduced model of the original scheme, consisting of claims, data, and warrants of arguments "to examine the learning of mathematics in the context of collective argumentation" (p.11). As suggested by Krummheuer (ibid.), during a classroom activity (or for the current study during group cooperation) one or more students could be contributing towards the formulation of the argument, attempting to convince the other participants of the group, including the class teacher (or the researcher). In previous papers (Patsiomitou, 2012b, p. 57), I have introduced and explained pseudo-Toulmin's model through examples in which (a) the data could be an element or an object of the dynamic diagram, and (b) a warrant could be a tool or a command that guarantees the result which is the claim (or the resulted formulation). The figure 7 presents a pseudo-Toulmin's model. A drawing of a square is the data (D), the theoretical dragging (Patsiomitou, 2011, p. 362) is the warrant (W), and the figure of the square is the claim (C). This means that a student can theoretically drag a point-vertex of a drawing-parallelogram and transform it into a figure-parallelogram, trying to acquire additional properties.

Also, I have extended the pseudo-Toulmin's model in order to express a relationship between the figures, something that I am going to present in the next sections. Using a pseudo-Toulmin model to represent the use of the tools in the same way is very important, as it helps the students to visualize the order in which the different tools are used in developing the construction, rendering the words unnecessary to explain it/ [or complementing the written description] and making it easier to conceptualise the problem.

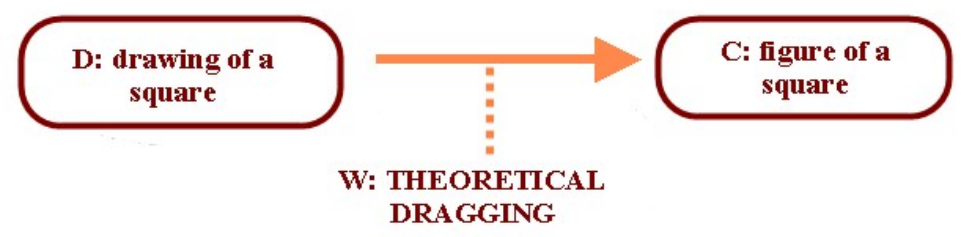

Figure 7. An example of a reduced pseudo-Toulmin's model (Patsiomitou, 2012b, p. 57)

In the next section, I shall present a proving process reported in Euclid' Elements. My aim is to examine various modes of constructional paths. Moreover, different paths of tools' use based on theorems and definitions of Euclidean Geometry by linking the steps in the constructional, transformational or explorative actions (or processes) in the proof via a sequence of actions using the different interaction techniques supported by the Geometer's Sketchpad DGS environment (Jackiw, 1991).

\section{Pseudo-Toulmin models for the analysis of Propositions in Euclid Elements}

Proposition 33 (Euclid's Elements, Book I): Straight lines joining equal and parallel (straight-lines) on the same sides are themselves also equal and parallel. (Fitzpatrick, 2007, p.35)

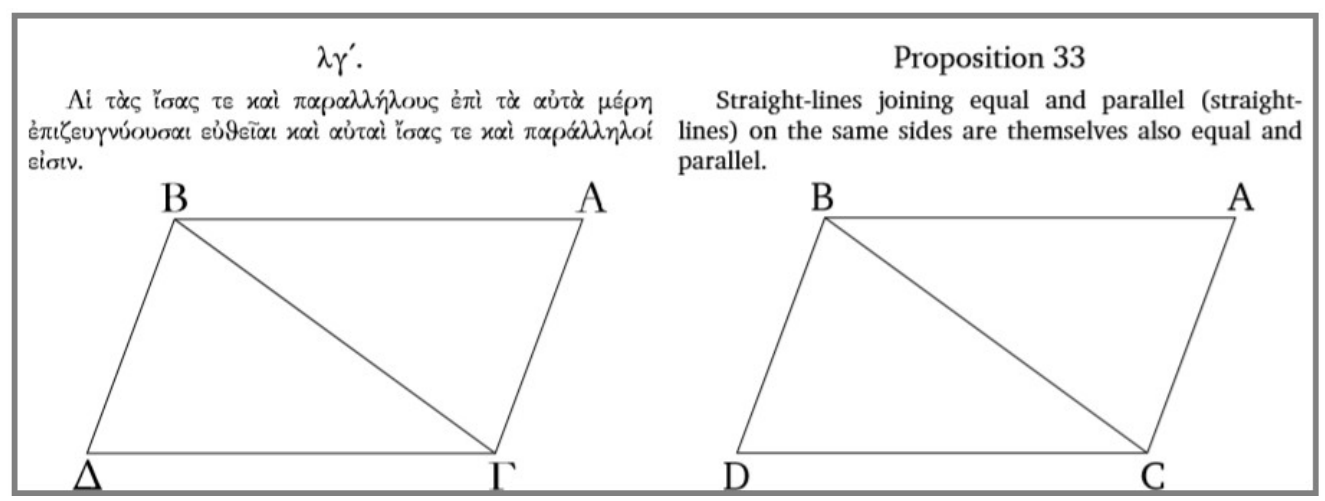

Figure 8. Proposition 33 (Euclid's Elements, Book I) (Fitzpatrick, 2007, p.35)

The following sequential diagrams are linking visual active representations of the mentioned above proposition. 


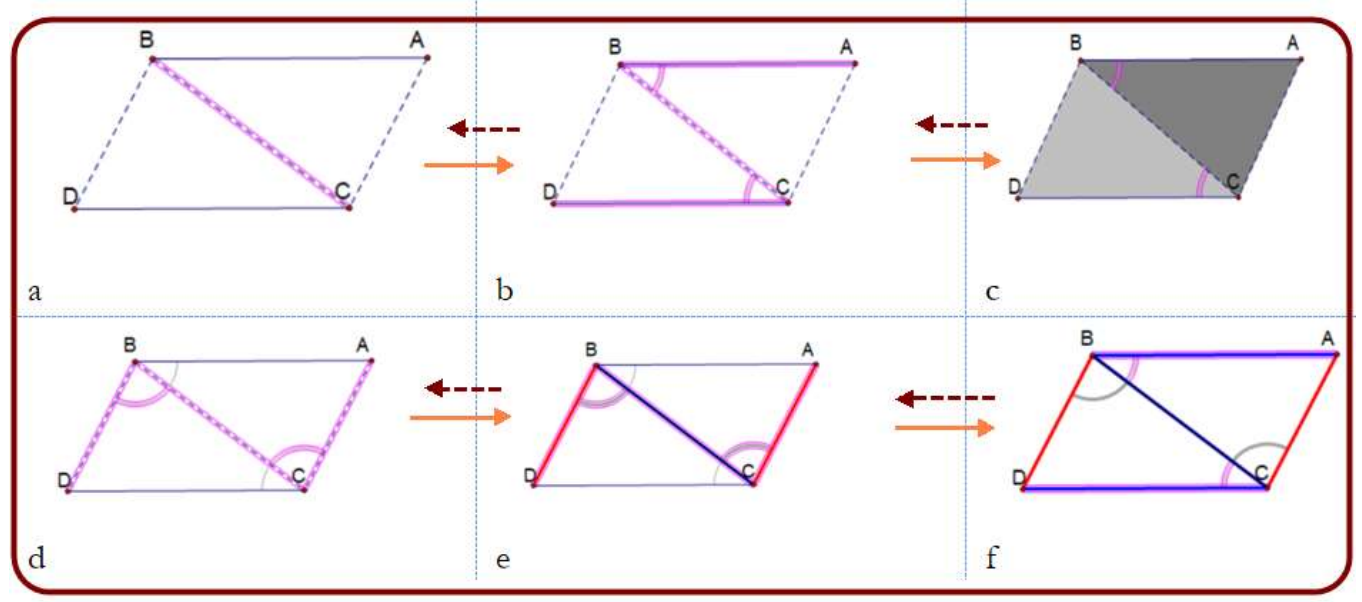

Figure 9. Linking visual active representations of a parallelogram's construction

The process can be described in the following steps: (a) Use of the "construct parallel line" tool for the construction of the arbitrary parallel segments AB, CD. (b) Use of the "Segment" tool for the construction of BC. (c) Use of the "Appearance custom tool" for the annotation of angles ABC, BCD. (d) Use of the "Construct the interior" tool for the annotation of the triangles $\mathrm{ABC}$ and $\mathrm{BCD}$. (e) Use of the "Appearance custom tool" for the annotation of angles DBC, BCA. (f) Use of the "Display colors" tool for the annotation of the segments BD, AC.

If we try to analyze the Proposition 33 (Euclid's Elements, Book I), using a Toulmin's model, the process can be described in a diagram in which the sequential utterances are linked in visual diagrammatic steps that can help students to visualize and verbalize the whole proposition. On a more detailed diagram we can incorporate the screenshots of the supportive propositions $(I .4,27,29)$ and the tools which scaffold the proving process (Figure $10)$.

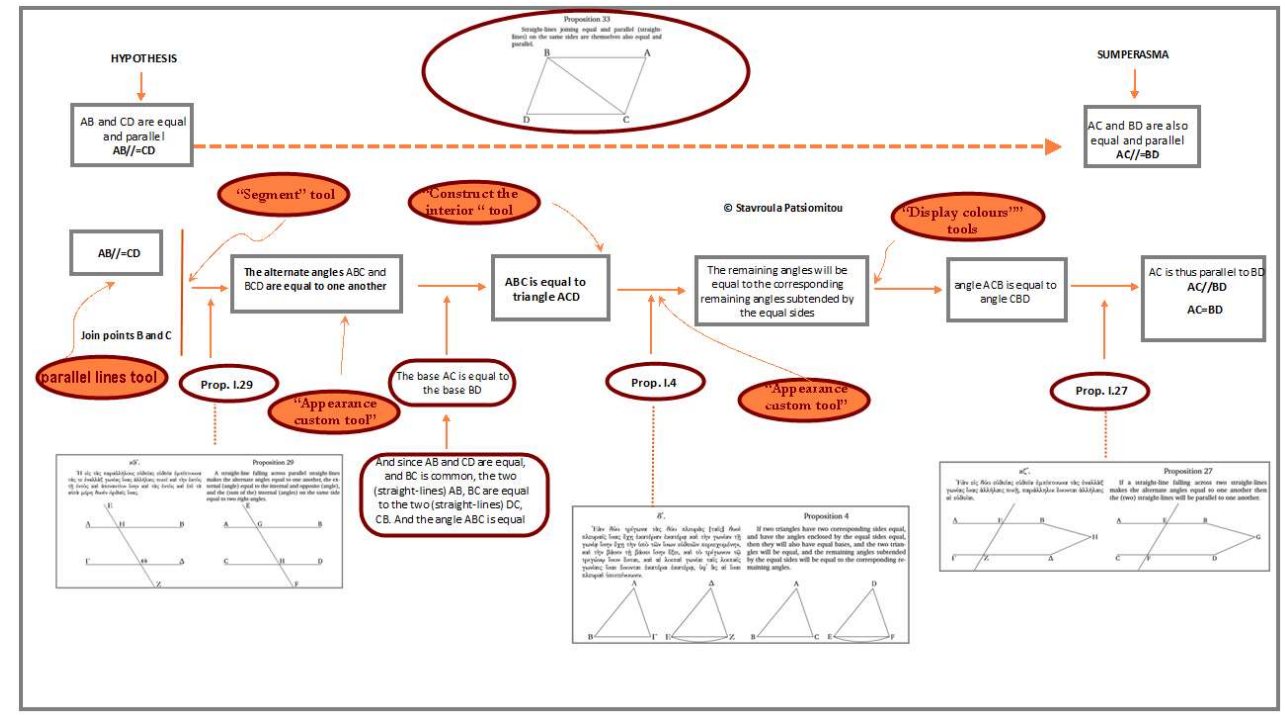

Figure 10. A pseudo-Toulmin diagram for the Proposition 33 (see also, Fitzpatrick, 2007, p.35)

The diagram includes two related steps of analysis: (a) the first is the analysis of the elements of the proof and (b) the second is the analysis of the sequential use of the tools. In the diagram there is a visible link between the elements or the components of the diagram and the particular statements in the Euclidean text (mentioned in Fitzpatrick, 2007, p.35).

Hanna (2000) reports Borwein, \& Jörgenson (1997) who mention many differences between the visual and the logical modes of presentation.

"Whereas a mathematical proof, as a sequence of valid inferences, has traditionally been presented in sentential mode, a visual representation purporting to constitute a 'visual proof' would be presented as a static picture. They point out that such a picture [...] would leave "the viewer to establish what is important 
(and what is not) and in what order the dependencies should be assessed" (Hanna, 2000, p.16).

How could we explain the whole process using the different tools of a DGS software? We can use a pseudoToulmin model in which a student could understand the use of the different tools and their supportive role for the development of the process. If we use the rotation tool, we can also construct a parallelogram via a more dynamic process (Figure 11a).

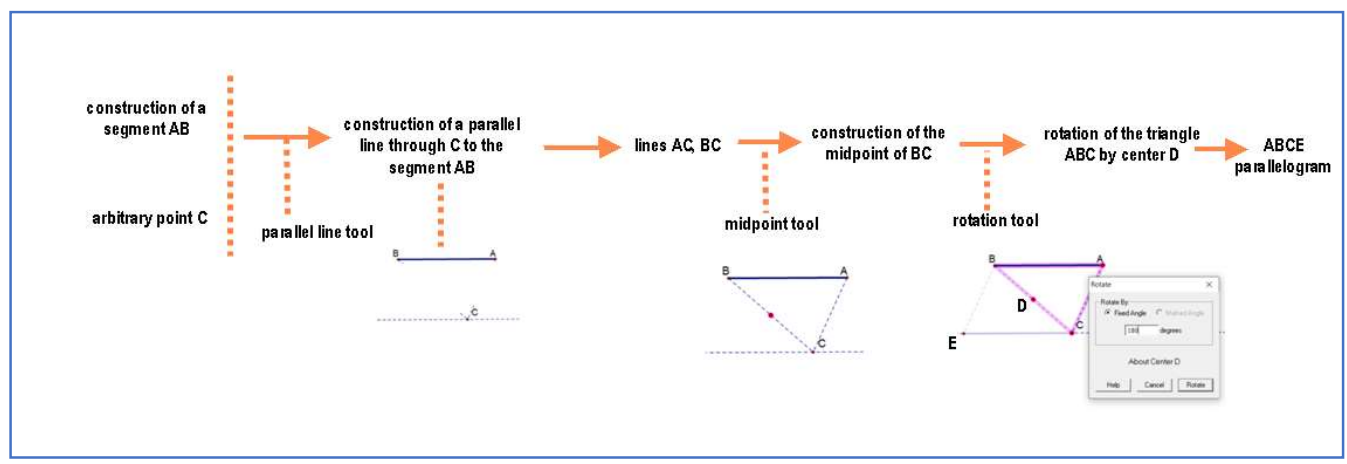

Figure 11a. A pseudo-Toulmin model for the analysis of the use of the tools in a DG software

A third process can be described in the figure $11 \mathrm{~b}$, in which the parallelogram can be constructed in a hybriddynamic way.

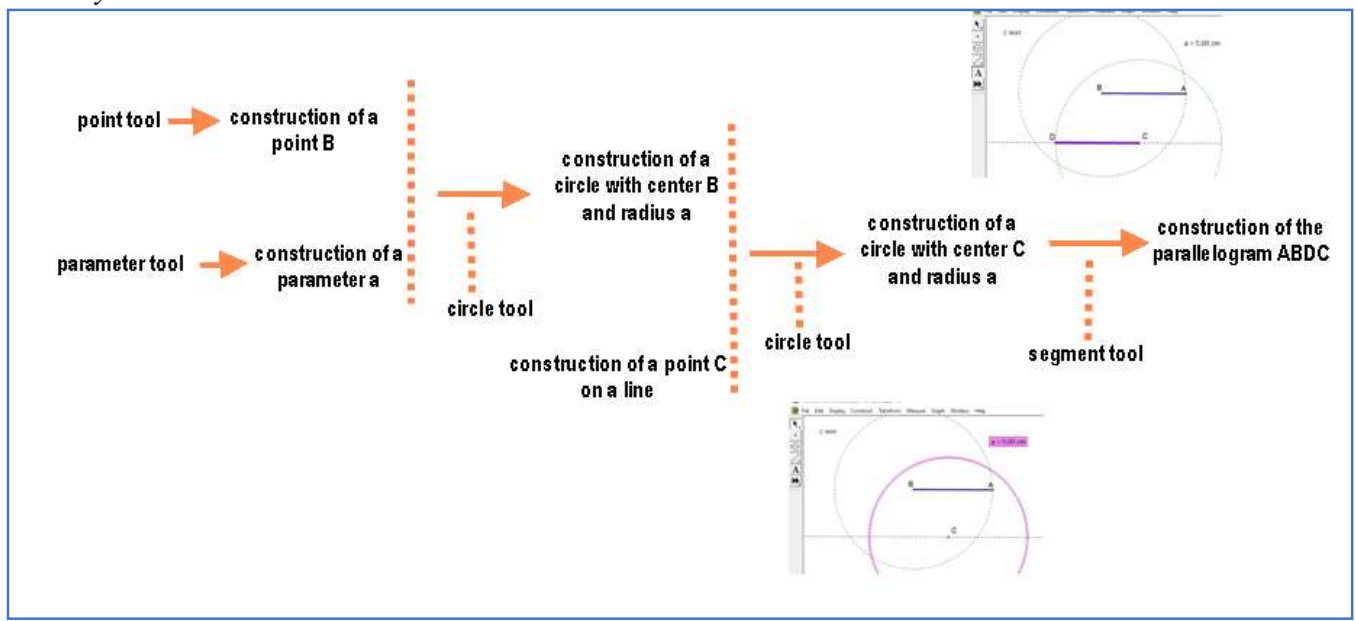

Figure 11b. A pseudo-Toulmin model for the analysis of a hybrid-dynamic process in a DG software

\section{Dividing a segment in (n) equal parts}

Problem A: Divide a given line segment into (n) equal parts.

The particular problem highlights the importance of orchestrating different digital tools or static means into a learning trajectory, which helps students, develop their understanding of the concept "divide into equal parts". Usually, I start my instructional approach as follows, creating figures on the board:

Researcher: Can you divide a segment to two congruent segments?

Student M1: We can construct the midpoint of the segment.

Student M2: We can construct the perpendicular line of the segment.

Researcher: Can we divide this segment into five equal parts?

Researcher: Firstly, we will draw the segment $A B$ which we will divide into five equal parts. Then, we shall draw a straight line Ay at any random/arbitrary angle with $\mathrm{AB}$. We will use the compass [or the straightedge] to take a point $\mathrm{C}$ on the line Ay. Then, we will construct the segments $\mathrm{AC}=\mathrm{CD}=\mathrm{DE}=\mathrm{EZ}$.. etc. We shall draw the line HB (Figure 12). Finally we will draw parallel lines to BH through the points D, E, Z.. etc. The intersections of these lines with the line $\mathrm{AB}$ will divide line $\mathrm{AB}$ into five equal parts.

Figure 12 illustrates the problem for the case $\mathrm{n}=5$, meaning the problem is: "Divide the line segment $\mathrm{AB}$ into five equal parts." The construction is based on the Proposition 9 (Euclid's Elements, Book VI). For this construction I used a straightedge and a compass. 


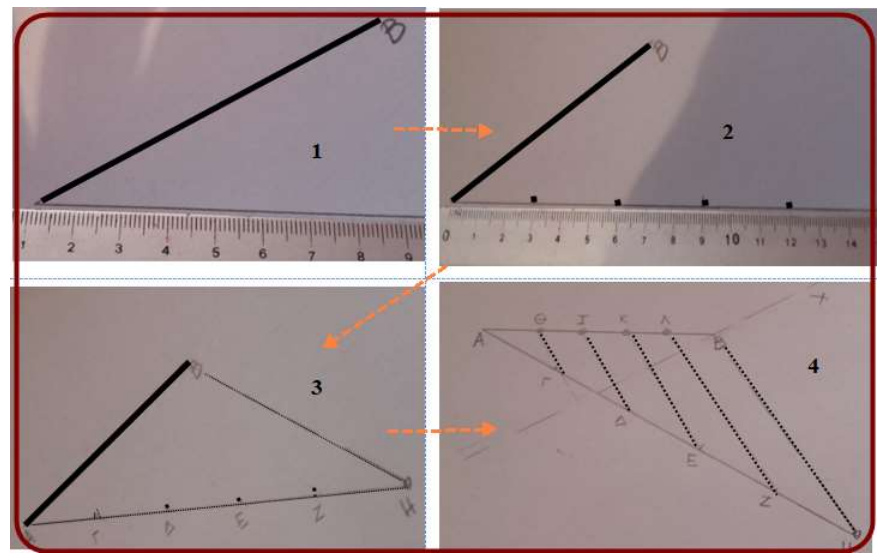

Figure 12. Division of the segment $\mathrm{AB}$ into five equal parts

Monaghan (2016) in his article "Doing Mathematics with tools: one task four tools" "illustrates a variety of mathematical and educational issues arising from doing a single task with different tools" (Monaghan, 2016, p. 13). According to Monaghan (2016, p. 14): "I now comment on aspects of mathematics, tools, actions and thought involved in this construction regarding tools: (1) There are two main physical tools used in this construction, a straight edge and a compass. I opened this section by praising the properties of the compass but the compass is of no use in this construction without the straight edge (I have underlined the word 'this' because the theorem of Mohr-Mascheroni proves that any construction made using a compass and straight edge can be constructed using a compass alone). This, to me, illustrates an important aspect of tool use (in mathematics or elsewhere), tools are rarely used in isolation, they are almost always used with other tools (though mathematicians, as in the case of the Mohr-Mascheroni theorem, value economy)".

The difficulty students face for the understanding of geometrical meanings led educators and researchers to find methods to represent them. Euclid's Elements is not an easy read for students in secondary-level classes. Oliver Byrne (1847) edited Euclid's Element in colors.

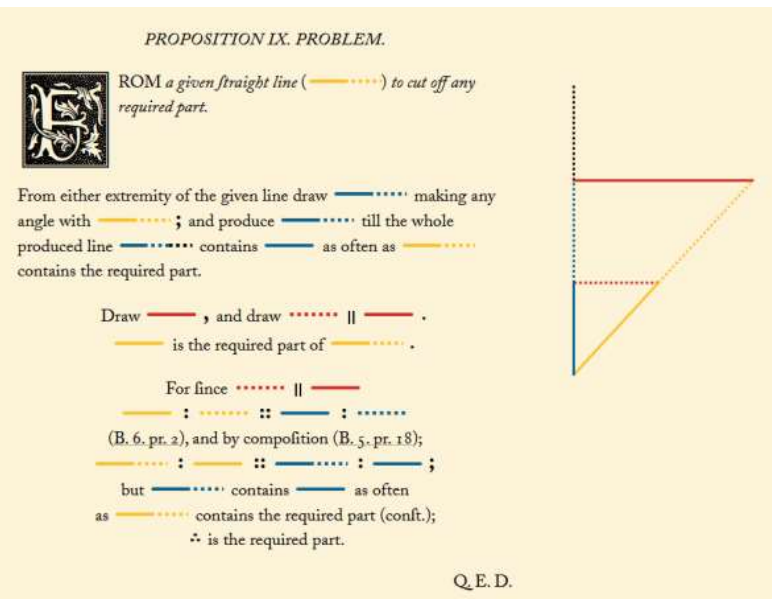

Figure 13. Proposition IX, Book VI (Byrne, 1847) (https:/www.c82.net/euclid/book6/)

As Bolondi, \& Luigini (2018) support “Byrne's idea was to present Euclid's statements, constructions and even proofs with a simple and (in a certain sense) rigorous use of colors-which in many situations synthesizes more explicit verbal descriptions and argumentations" (Bolondi, \& Luigini, 2018, p. 1468)

\section{Dividing a segment in (n) equal parts in a DGS environment}

Problem B: Divide a segment in (n) equal parts in a DGS environment

When students use static means, they are able to measure the length of side 'a' with a ruler. Afterwards they are able to use this measurement given that they know the geometrical properties of the figure whose one side is equal to a. This "measurement" method is not the method the software demonstrates for constructing a figure which does not mean that a DGS software faces a functional disadvantage comparing it with static means. 


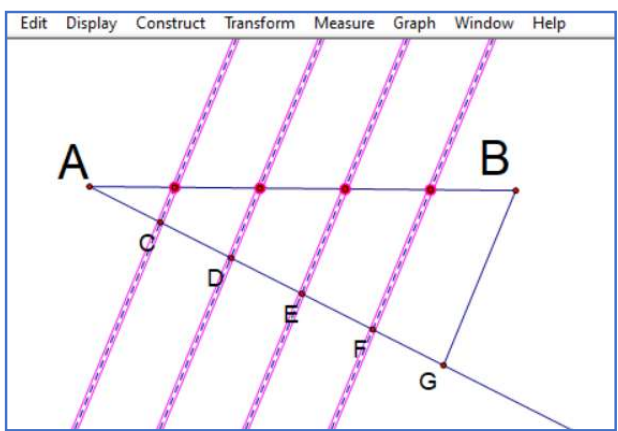

Figure 14. Dividing the segment $\mathrm{AB}$ in five equal parts

A first different mode is the construction of points at equal distances using the translation tool in a DGS environment. The pop-up menu plays an important role in the construction of the next point. We can drag the point $\mathrm{C}$ (Figure 14). This action affects the transformation of the orientation of the dashed lines, but the equal distances on the segment $\mathrm{AB}$ between the points remain stable or "as objects are moved, they maintain dependencies" (Stahl, 2013, p.7).

A second mode can be achieved using a parametric segment $\mathrm{j}$. I constructed sequential circles: one with center $\mathrm{A}$ and radius $\mathrm{j}$ that meets the side of the arbitrary but convenient angle at point $\mathrm{C}$, then a circle with centre $\mathrm{C}$ and radius $\mathrm{j}$, and so on (Figure 15). Then we continue by connecting the point $\mathrm{G}$ with the point $\mathrm{B}$ and drawing the parallel lines from the points F, E, D, C to the segment GB. Point C is a hybrid-dynamic object, since it cannot be dragged. If we drag the segment $\mathrm{j}$, then the distance between the segments $\mathrm{AC}, \mathrm{CD}$, etc. will be transformed equally, but the equal distances on segment $\mathrm{AB}$ remain the same [meaning the distance between the points at which the segment $\mathrm{AB}$ has been divided]. The family of parallel lines is moved together, following the movement of the segment $\mathrm{BH}$. This means that dragging $\mathrm{j}$ preserves the distances of the equal segments between $\mathrm{A}$ and $\mathrm{B}$ (even if the distances between the points $A, C, \ldots$ are modified by the dragging of $\mathrm{j}$ ).

A third mode is by using a parameter $\mathrm{t}_{1}$ (Figure 15). We can choose to construct a segment for example with length equal to $2 \mathrm{~cm}$, or with such a length as we wish. These parametrical segments can be transformed dynamically by transforming (e.g., by using animation) the parameters with which they have been created, meaning the parental objects in a continuous/or not process (Patsiomitou, 2019b, p.40):

- Firstly, the animation on parameters turns the dynamic diagram to a more detailed and complex representation than the one we have created using the tools (e.g., segments, lines and circles).

- Secondly, the concept of parameters belongs to algebra. On the other hand, when we create a figure in a static environment, we never use a parameter to create the figure, just as we never define a segment as a parameter for use in our construction. Moreover, animating the parameters transforms the synthesis of the diagram into an "infinite" number of snapshots, which the user would probably not consider manipulating by her/himself.

This is a second level construction according to van Hiele theory, as it includes an abstract process. What are the objects of the constructions? They are the point $\mathrm{A}$ and a parameter $\mathrm{t}_{1}$ (i.e., an algebraic parameter). If we alternate the value of the parameter $t_{1}$ (for example we can make it $1 \mathrm{~cm}$ ), then the distance between the segments $A C, C D$, etc. will be transformed equally, but the equal distances remain the same [between the points that the segment $\mathrm{AB}$ has been divided]. This way of construction is in a more abstract level than the previous way, as the student is pushed through the process to a reification of sequential nested objects (Patsiomitou, 2019c, p. 80).

This action has a presupposition: the students to know in advance that a side of triangle is a segment or to understand the double role of the objects (van Hiele level 3). Moreover, the orientation of the sides may generate a cognitive obstacle, especially for students at van Hiele levels 1 or 2 . This is because students very often fail to recognize the modification of the orientation of tools due to a lack of place way apprehension during the instrumental decoding process. The custom tools help them to simplify the construction process. If we try to create the diagrams of this construction, we shall see the different paths that our mind can use for the same construction. As we can see from the modes of the construction described above, a student has a plethora of ways to achieve the division of segment to equal parts, something that cannot be done in a static environment. I absolutely agree with Stahl (2013) who argues that "dependencies lie at the heart of Euclid's geometry, but they have been largely buried in the traditional understanding of geometry" (p.13). 


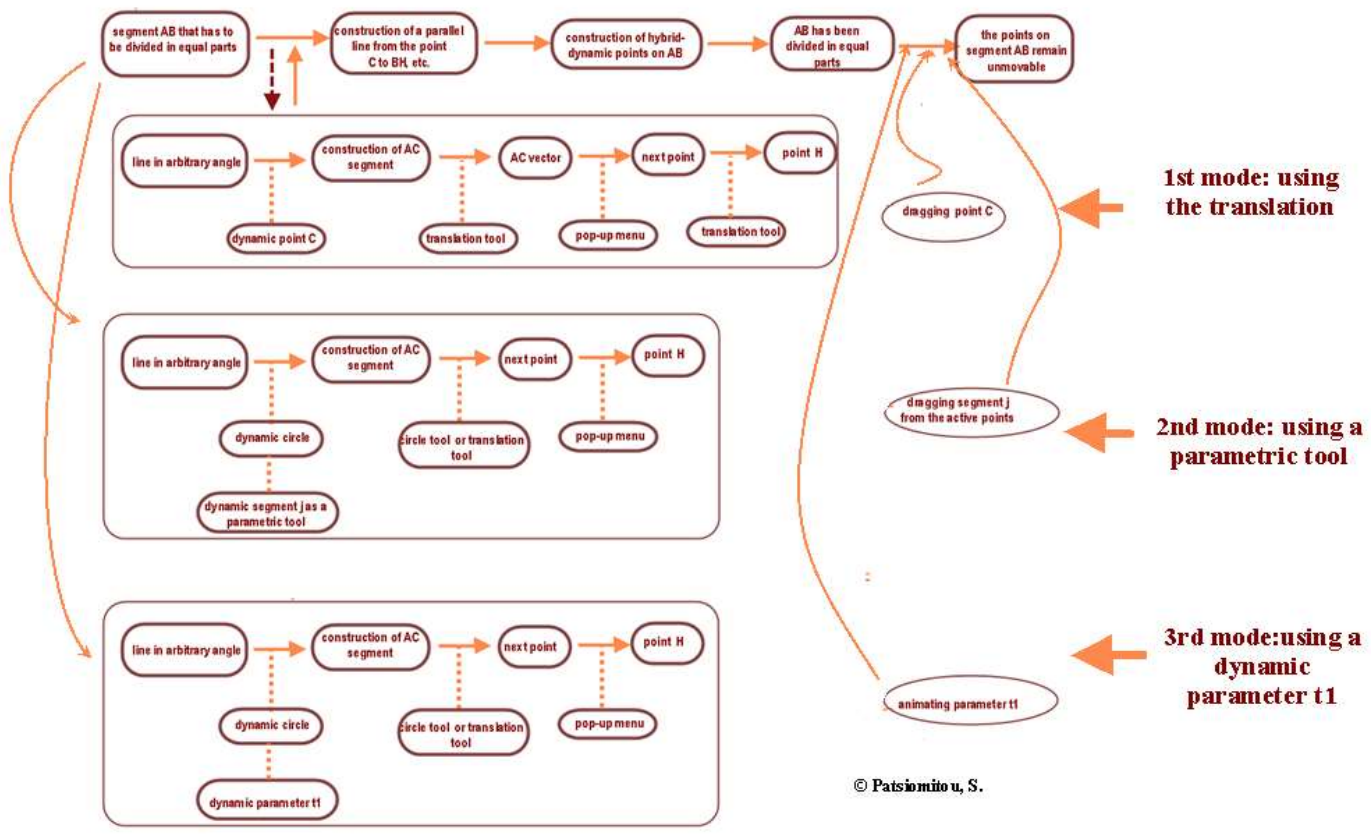

Figure 15. The three modes of construction as an interdependence of tools and mathematical objects

\section{Dividing an angle in (n) equal parts in a DGS environment}

Since any angle can be bisected using a straight edge and a compass, dividing any angle into any number of equal parts was a problem, originally proposed by the mathematicians of ancient Greece (see also Brikas, 1970; Mourmouras, 1999). Buckley \& MacHale (1985) point out, that "it was only with modern algebraic techniques in the $19^{\text {th }}$ century that it was shown conclusively that no such construction can exist" (p.9). Mavrikios Brikas (1970) argues "Ancient Greek mathematicians tried to trisect an arbitrary angle, or generally to divide it into p equal parts (where $p$ is a prime number). In this way, they could construct any regular polygon. Nevertheless, their attempts to construct an enneagon (9-gon) by trisecting the central angle of an equilateral triangle (inscribed in a circle) proved fruitless. Hippias of Elia (460 B.C.E.) created a Quadratrix for the trisection of an angle (as mentioned by Proklos). [...] Consequently, in order to trisect an angle u, once we have constructed the Quadratrix, we have to trisect the coordinate y of the point $P^{\prime \prime}$ (p. 109)" (my translation from the Greek text).

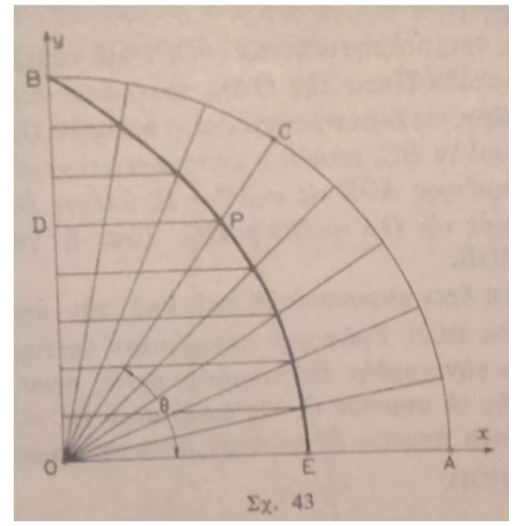

Figure 16a. Hippias' Quadratrix (Mavrikios Brikas, 1970, p. 109)

Can we construct an angle's trisection in a DGS environment? Harper, \& Driskell (2010) describe in details how to construct a trisection of an angle in the Geometer's Sketchpad, having first described the construction of "Hippias' Quadratrix". An interpretation of the description of the construction of Hippias' Quadratrix in the form of sequential pseudo-Toulmin diagrams [with tools interconnected] can be viewed in figure 16b. 


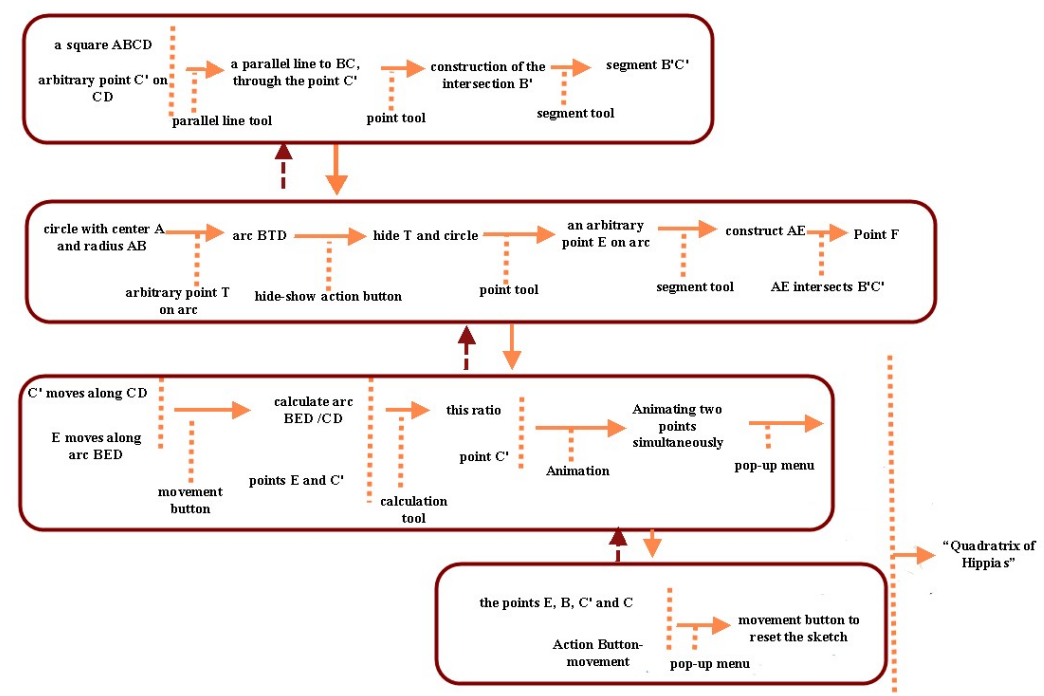

Figure 16b. The interdependencies in the diagrammatical representation of the construction of the "Quadratrix of Hippias" (see also, the study of Harper \& Driskell, 2010)

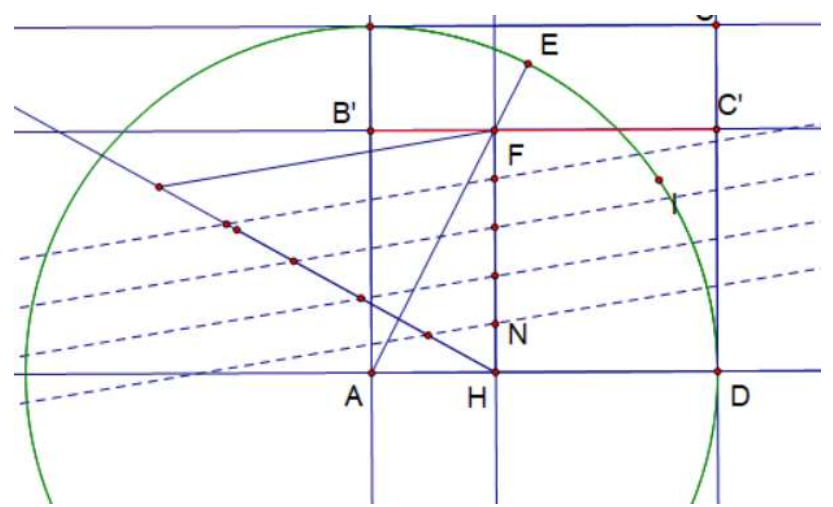

Figure 17. Dividing the segment HF into 5 equal parts

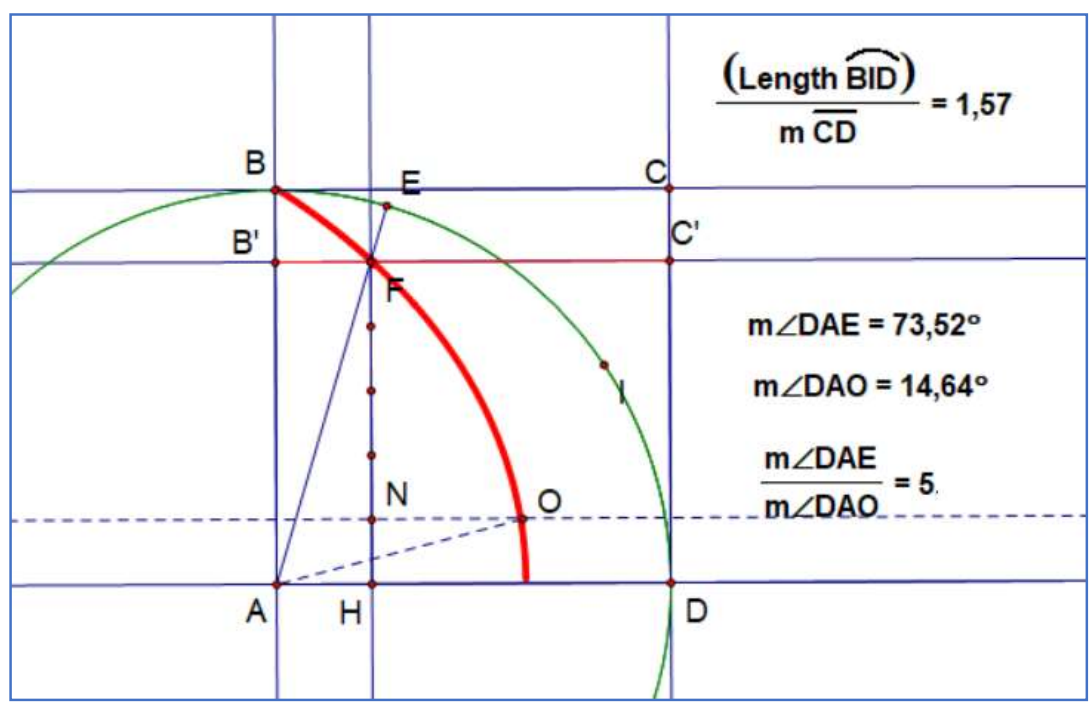

Figure 18. Dividing the angle DAE into five equal parts 
I divided the segment HF into five equal parts (Figure 17), using the first mode for the division of a segment, mentioned in the section 6 (Figure 15). The construction of the parallel line NO to AD, intersects the Quadratrix to the point $\mathrm{O}$. The angle DAO is one fifth of the angle DAE (Figure 18). The important thing here is the way that these sequential constructions are dependent to each other. As Stahl (2013) supports (a) "The construction sequences are used to establish dependencies" (p.1) and (b) "the construction of dependencies is central to deductive cognition" (p.1).

\section{Dynamic Euclidean Geometry: pseudo-Toulmin modeling instructional learning paths}

The Didactics of Mathematics is a complex scientific area which focuses mainly at the interaction between two main systems: the system of teaching, and the system of learning mathematical objects. The Didactics of Geometry, as part of the Didactics of Mathematics, focuses on the didactic methods of geometry, using multiple representational systems with static or dynamic tools in synchronous or asynchronous teaching.

Didactics of Mathematics' [using ICT] is the science and art of teaching and learning mathematics, designing and implementing teaching and instructional products for the learning of mathematics in static or computing environments, incorporating the content of the subject of mathematics, mathematics pedagogy, the history of mathematics, and psychological theories of learning, teaching and human-computer interactions (Patsiomitou, 2019c, p.5).

In the current study I analyzed, using instrumental decoding and pseudo-Toulmin modeling, several conceptual and instrumental learning trajectories for the teaching of, or the conducting of action research into Geometry, which employ digital dynamic means: in other words, the construction of instrumental learning trajectories within "Dynamic Euclidean Geometry". Didactics of Geometry supports the construction of hypothetical learning trajectories and learning progressions. In my research study "Students'learning progression through instrumental decoding of mathematical ideas" (Patsiomitou, 2014), I created an adaptation of Simon's (1995) Mathematics Teaching Cycle, examining the use of technology in the teaching cycle which plays an important role in the development of mathematical discussions (Patsiomitou, 2014, p.35). The analysis of the teaching situations has led to an iterative diagram that was an adaptation of Simon's (1995, p.136) work, taking into account also the work of McGraw (2002, p.10).

The Mathematics Teaching Cycle portrays the relationship between the following areas of knowledge (Simon, 1995):

“the teacher's knowledge of mathematics and his hypotheses about the students' understandings, several areas of teacher knowledge come into play, including the teacher's theories about mathematics teaching and learning; knowledge of learning with respect to the particular mathematical content; and knowledge of mathematical representations, materials, and activities" (p. 133).

As it is well known the development of student's thinking is depended on the structure of the content of the instructional process. From that point of view the structure of the design of the activities and their sequence during the implementation process plays the main role. The teacher's interaction with students and the mathematical communication through dialogues is accomplished in sequential situations: the implementation of activities, effective teaching and inquiry into students' mathematics, the assignment of students' knowledge, all of which leads to the teacher's feedback. These processes go on continually and can suggest adaptations in various domains of a teacher's knowledge, including in the following areas: mathematics, pedagogy, representations, technology, and modeling through LVAR representations. The whole process leads to a modification of the hypothetical learning path that includes a continuous interaction between the teacher's knowledge of particular content, the teacher's goal, and assessment of the students' levels.

Today, I will complement the diagram (Figure 19), by adding a column in the middle. In this column, I note the role of instrumental decoding in a static or dynamic environment, and how the competence of the participants (students -teacher) can influence/impact the holistic result of the learning process by creating interdependencies/intra-dependencies during the construction of instrumental learning trajectories. Moreover, I point out that: (a) The notion of LVAR is directly linked to the notion of instrumental decoding; (b) A dynamic diagram expresses the interdependencies between dynamic objects; (c) A dynamic section expresses the intradependencies / interdependencies between dynamic diagrams and mathematical objects. This is also the core idea of this research study: the construction of dynamic interdependencies between dynamic objects (or hybrid dynamic objects) diagrams or sections lies at the heart of the construction of instrumental learning paths. 


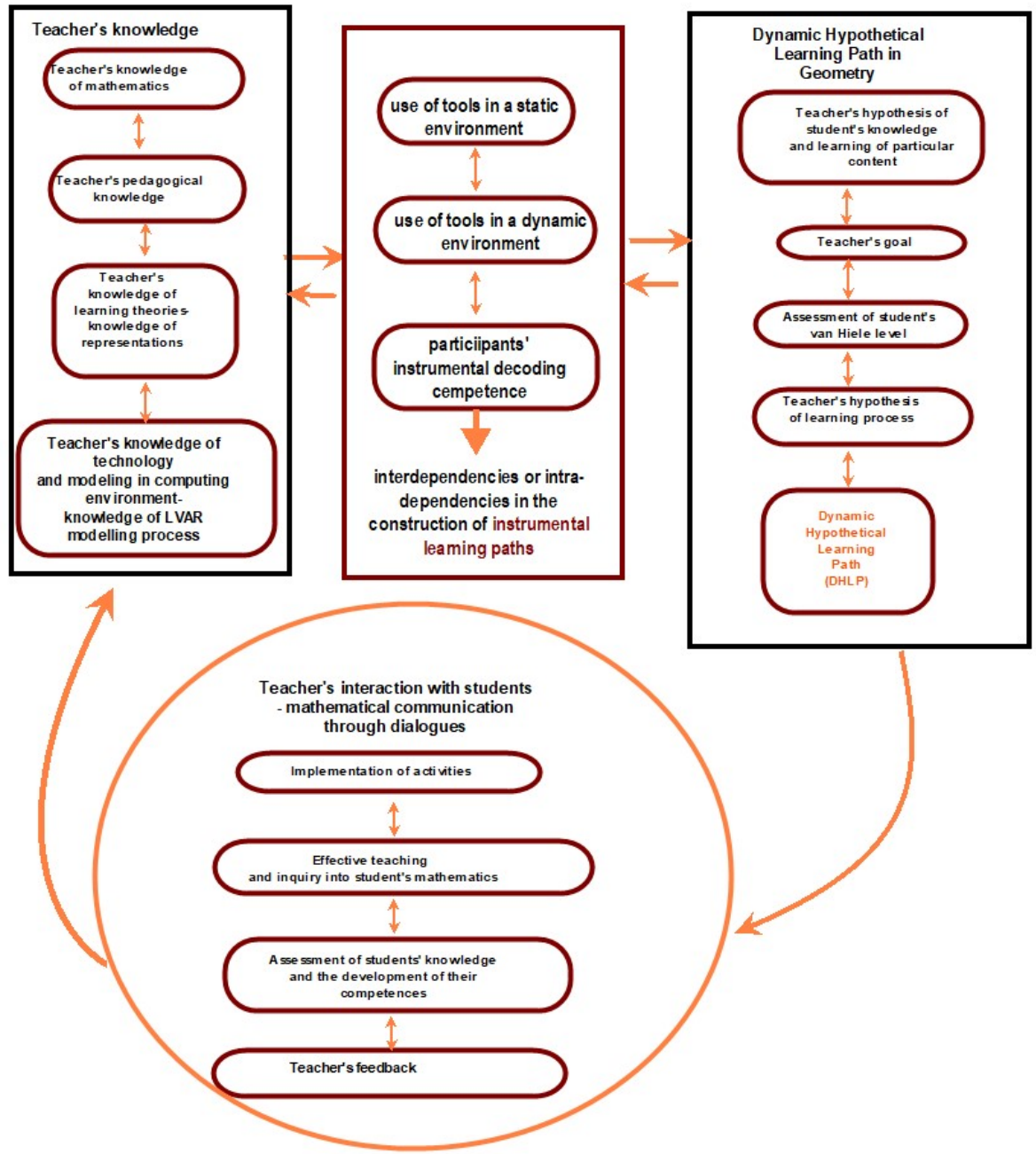

Figure 19. An adaptation of Simon's (1995) Mathematics Teaching Cycle for the current study incorporating the notion of "instrumental learning paths"

\section{References}

Bolondi, G., Luigini, A. (2018) Byrne's Euclidean Geometry Revisited with Geogebra. In: Cocchiarella L. (eds). In the Proceedings of the 18th International Conference on Geometry and Graphics. Advances in Intelligent Systems and Computing, vol 809. Springer, Cham, https://doi.org/10.1007/978-3-319-95588-9_129

Brikas, Mavrikios, A. (1970). The famous unsolved geometrical problems of Ancient Greece, Athens, Greece.

Stephen Buckley and Desmond Machale (1985). Dividing an angle into equal parts. The Mathematical Gazette, Vol. 69, No. 447: pp. 9-12, https://doi.org/10.2307/3616440

Byrne, O. (1847): The first six books of the elements of Euclid in which coloured diagrams and symbols are used instead of letters for the greater ease of learners. William Pickering, London

Clements, D. \& Sarama, J. (2004). Learning trajectories in mathematics education. Mathematical Thinking and Learning, 6(2), 81-89.

Duval, R. (1995a). Sémiosis et pensée humaine. Berne: Peter Lang

Duval, R. (1995b). Geometrical Pictures: kinds of representation and specific processing. In R. Sutherland and J. Mason (Eds), Exploiting Mental Imagery with Computers in Mathematics Education. Berlin: Springer. pp. 142-157

Duval, R. (1999). Representation, vision and visualization: Cognitive functions in mathematical thinking. Basic issues for learning. In F. Hitt \& M. Santos (Eds.), Proceedings of the 21st Annual Meeting of the North American Chapter of the International Group for the Psychology of Mathematics Education, Volume 1 (pp. 3-26). Cuernavaca, Morelos, Mexico.

Fischbein, E. (1993) The theory of figural concepts. Educational Studies in Mathematics, 24(2), 139-162.

Fitzpatrick, R. (2007). Euclid's Elements of geometry. Morrisville, NC: Lulu.

Fuys, D., Geddes, D., \& Tischler, R. (1988). The Van Hiele model of thinking in geometry among adolescents. Journal for Research in Mathematics Education. Monograph, Vol. 3, pp. 1-196. Published by: National Council of Teachers of Mathematics Stable URL: http://www.jstor.org/stable/749957 Accessed: 03/11/2013. 
Fuys, D., Geddes, D., \& Tischler, R. (Eds). (1984). English translation of selected writings of Dina van Hiele-Geldof and Pierre M. van Hiele. Brooklyn: Brooklyn College. (ERIC Document Reproduction Service No. ED 287 697).

Gawlick, T. (2005). Connecting arguments to actions -Dynamic geometry as means for the attainment of higher van Hiele levels. Zentralblatt für Didaktik der Mathematik, 37(5), 361-370.

Goldenberg, P., \& Cuoco, A. (1996). What is dynamic geometry? In R. Lehrer \& D. Chazan (Eds.), Designing learning environments for developing understanding of geometry and space (pp. 351-368). Mahwah, NJ: Lawrence Erlbaum Associates.

González G., Herbst P. (2009) Students' conceptions of congruency through the use of dynamic geometry software International Journal of Computers for Mathematical Learning. 14 (2) 153-182.

Hanna, G. (2000). Proof, Explanation and Exploration: An Overview'. Educational Studies in Mathematics. 44(1/2), pp. 5-23.

Suzanne Harper and Shannon Driskell (2010). "An Investigation of Historical Geometric Constructions - Using the Quadratrix to Trisect an Angle," Convergence (August 2010). https://www.maa.org/press/periodicals/convergence/aninvestigation-of-historical-geometric-constructions-using-the-quadratrix-to-trisect-an-angle

Hegedus, S. (2005). Dynamic representations: A new perspective on instrumental genesis. In M. Bosch (Ed.), Proceedings of CERME4, The Fourth Congress of the European Society for Research in Mathematics Education, Barcelona, Spain: Ramon Lull University

Hohenwarter, M. (2001). GeoGebra [Computer software]. FCR-STEM, Learning Institute, Florida State University. http://www.geogebra.org/cms/.

Hollebrands, K., Laborde, C., \& Sträßer, R. (2008). Technology and the learning of geometry at the secondary level. Research on Technology and the Teaching and Learning of Mathematics, 1, 155-205. Greenwich CT: Information Age.

Jackiw, N. (2009). Dynamic Geometry-Sketchpad's Big Idea. Spark! Teaching Mathematics with the Geometer's Sketchpad. Emeryville, CA: Key Curriculum Press. http://gsp5.s3.amazonaws.com/GSP5_Spark.pdf

Jackiw, N., \& Sinclair, N. (2009). Sounds and pictures: dynamism and dualism in dynamic geometry. ZDM-The International Journal on Mathematics Education, 41(4), 413-426.

Jackiw, N. (1991). The Geometer's Sketchpad [Computer Software]. Berkeley, CA: Key Curriculum Press

Predrag Janicic, Julien Narboux, Pedro Quaresma (2012). The Area Method: a Recapitulation. Journal of Automated Reasoning, Springer Verlag, 2012, 48 (4), pp.489-532. 10.1007/s10817-010-9209-7. hal-00426563v2

Janvier, C. (1987). Problems of Representations in the Learning and Teaching of Mathematics. New Jersey: Lawrence Erlbaum Associates.

Krummheuer, G. (1995). The ethnography of argumentation. In P. Cobb \& H. Bauersfeld (Eds.), The emergence of mathematical meaning: Interaction in classroom cultures (pp. 229-269). Hillsdale, NJ: Lawrence Erlbaum Associates.

Laborde, J. M. (2004). Cabri 3D. Online at: http://www.cabri.com/

Laborde, J-M., Baulac, Y., \& Bellemain, F. (1988) Cabri Géomètre [Software]. Grenoble, France: IMAG-CNRS, Universite Joseph Fourier

Lopez-Real, F.J. \& Leung, A. (2004). The conceptual tools of Euclidean and dynamic geometry environments, Paper presented in Topic Study Group 10: Research and development in the teaching and learning of geometry, ICMI 10. Copenhagen, Demark.

McGraw, R. H. (2002). Facilitating whole-class discussion in secondary mathematics classrooms. Unpublished doctoral dissertation, Indiana University, Bloomington, IN.

Monaghan, J. (2016). Doing Mathematics with Tools: One Task, Four Tools. In J. Monaghan, L. Trouche, \& J. M. Borwein (Eds.), Tools and Mathematics (pp. 13-22). Cham: Springer International Publishing.

Mourmouras, D. (1999) Euclid Elements. http://www.physics.ntua.gr/ mourmouras/euclid/index.html

Pape, S., \& Tchoshanov, M. (2001). The role of representation(s) in developing mathematical understanding. Theory into Practice, 40(2), 118-125.

Patsiomitou, S. (2005). Fractals as a context of comprehension of the meanings of the sequence and the limit in a Dynamic Computer Software environment. Master Thesis. Department of Mathematics. National and Kapodistrian University of Athens. Interuniversity Postgraduate Program. http://www.math.uoa.gr/me/dipl/dipl_patsiomitou.pdf

Patsiomitou, S. (2006): Transformations on mathematical objects through animation and trace of their dynamic parameters. Proceedings of the 5th Pan-Hellenic Conference with International Participation. Informatics and Education-ETPE, pp. 1070-1073, Thessaloniki. ISBN 960-88359-3-3. http://www.etpe.gr/custom/pdf/etpe1213.pdf

Patsiomitou, S., (2008a). The development of students' geometrical thinking through transformational processes and interaction techniques in a dynamic geometry environment. Issues in Informing Science and Information Technology journal. Vol. 5, pp. 353-393. https://doi.org/10.28945/1015

Patsiomitou, S. (2008b) Linking Visual Active Representations and the van Hiele model of geometrical thinking. Proceedings of the 13th Asian Conference in Technology in Mathematics. pp 163-178. ISBN 978-0-9821164-1-8. Bangkok, Thailand: Suan Shunanda Rajabhat University. Available on line http://atcm.mathandtech.org/EP2008/papers_full/2412008_14999.pdf

Patsiomitou, S. (2008c) Do geometrical constructions affect students' algebraic expressions? Proceedings of the 13th Asian Conference in Technology in Mathematics. pp 193-202. ISBN 978-0-9821164-1-8. Bangkok, Thailand: Suan Shunanda Rajabhat University.

Patsiomitou, S. (2008d) Custom tools and the iteration process as the referent point for the construction of meanings in a DGS environment. Proceedings of the 13th Asian Conference in Technology in Mathematics. pp. 179-192. ISBN 978-0- 
9821164-1-8. Bangkok, Thailand: Suan Shunanda Rajabhat University.

Patsiomitou, S. (2010) Building LVAR (Linking Visual Active Representations) modes in a DGS environment. Electronic Journal of Mathematics and Technology (eJMT), pp. 1-25, Issue 1, Vol. 4, February, 2010, ISSN1933-2823.

Patsiomitou, S. (2011) Theoretical dragging: A non-linguistic warrant leading to dynamic propositions. In Ubuz, B (Ed.). Proceedings of the 35th Conference of the International Group for the Psychology of Mathematics Education, Vol. 3, pp. 361-368. Ankara, Turkey: PME. ISBN 978-975-429-297-8.

Stavroula Patsiomitou (2012a). The development of students' geometrical thinking through transformational processes and interaction techniques in a dynamic geometry environment. $\mathrm{PhD}$ thesis. University of Ioannina (December 2012).

Patsiomitou, S. (2012b) A Linking Visual Active Representation DHLP for student's cognitive development. Global Journal of Computer Science and Technology, Vol. 12 Issue 6, March 2012. pp. 53-81. ISSN 9754350. Available online at: http://computerresearch.org/index.php/computer/article/view/479/479

Patsiomitou, S. (2014). Student's Learning Progression Through Instrumental Decoding of Mathematical Ideas. Global Journal of Computer Science and Technology, Vol. 14 Issue 1, pp. 1-42. Online ISSN: 0975-4172 \& Print ISSN: 09754350.http://computerresearch.org/index.php/computer/ article/view/41/41

Patsiomitou, S. (2018). An 'alive' DGS tool for students' cognitive development. International Journal of Progressive Sciences and Technologies (IJPSAT) ISSN: 2509-0119. Vol. 11 No. 1 October 2018, pp. 35-54. http://ijpsat.ijshtjournals.org/index.php/ijpsat/article/view/636

Patsiomitou, S. (2019a). From Vecten's Theorem to Gamow's Problem: Building an Empirical Classification Model for Sequential Instructional Problems in Geometry. Journal of Education and Practice. Vol.10, No.5, pp.1-23.DOI: 10.7176/JEP/10-5-01. https://iiste.org/Journals/index.php/JEP/article/view/46479

Patsiomitou, S. (2019b). Hybrid-dynamic objects: DGS environments and conceptual transformations. International Journal for Educational and Vocational Studies. Vol. 1, No. 1, May 2019, pp. 31-46. DOI: https://doi.org/10.29103/ijevs.v1i1.1416.

Patsiomitou, S. (2019c). A Trajectory for the Teaching and Learning of the Didactics of Mathematics [using ICT]: Linking Visual Active Representations. Monograph. Published by Global Journal Incorporated. United States. ISBN: 978-17340132-0-7 (in English). http://doi.org/10.34257/SPatTrajICT

Pedemonte, B. (2007). How can the relationship between argumentation and proof be analysed? Educational Studies in Mathematics, 66, 23-41.

Peirce, C. S. (1998, c. 1903d). The three normative sciences. In N. Houser \& C. Kloesel, (Eds.), The Essential Peirce: Selected philosophical writings, Volume 2, 196-207. Bloomington: Indiana University Press.

Rabardel, P. (1995). Les hommes et les technologies, approche cognitive des instruments contemporains. Paris: Armand Colin.

Richter-Gebert, J. and Kortenkamp, U. (1999). User manual of the Interactive Geometry Software Cinderella. Springer-Verlag, Heidelberg

Sedig, K., \& Sumner, M. (2006). Characterizing interaction with visual mathematical representations. International Journal of Computers for Mathematical Learning, 11, 1-55. New York: Springer

Simon, M. A. (1995). Reconstructing mathematics pedagogy from a constructivist perspective. Journal for Research in Mathematics Education, 26 (2), 114-145.

Skemp, R. (1986). The psychology of learning mathematics (2nd ed.) Harmondsworth, UK: Penguin

Stahl, G. (2013). Translating Euclid: Liberating the cognitive potential of collaborative dynamic geometry. Web: http://gerrystahl.net/pub/translating.pdf

Toulmin, S.E. (1958). The uses of argument. Cambridge: Cambridge University Press.

Trouche, L. (2003). From Artifact to Instrument: Mathematics Teaching Mediated by Symbolic Calculators, in P. Rabardel and Y. Waern (eds), Interacting with Computers, vol.15 (6).

Trouche, L. (2004). Managing the complexity of the human/machine interaction in computerized learning environments: guiding students' command process through instrumental orchestrations. International Journal of Computers for Mathematical Learning 9, pp. 281-307, Kluwer academic publishers

Venema, G. A. (2005/2012). The Foundations of Geometry (2nd edition). Upper Saddle River, NJ: Pearson Prentice Hall.

White, P., \& Mitchelmore, M. C. (2010) Teaching for abstraction: A model. Mathematical Thinking and Learning. 12(3), 205226

Whiteley Walter (1999). The Decline and Rise of Geometry in 20th Century North America. Proceedings of the 1999 CMESG Conference. http://www.math.yorku.ca/ whiteley/cmesg 